\title{
Identification and pathogenicity of a variant porcine epidemic diarrhea virus field strain with reduced virulence
}

Xiangbin Zhang ${ }^{1,3}$, Yongfei Pan², Dongdong Wang ${ }^{2}$, Xiaoyan Tian ${ }^{2}$, Yanhua Song ${ }^{2^{*}}$ and Yongchang Cao ${ }^{1^{*}}$

\begin{abstract}
Background: Since 2010, a variant Porcine epidemic diarrhea virus (PEDV), which causes an acute, highly contagious, and devastating viral enteric disease with a high mortality rate in suckling pigs, broke out in China and spread rapidly to neighboring countries, even to the North America. This virus gradually became the main subtype of PEDV worldwide. However, there were no reports of mild pathogenicity of a variant porcine epidemic diarrhea virus in China.
\end{abstract}

Findings: In 2013, a PEDV-positive sample from a sow with very mild clinical sign was used to inoculate in Vero cells to isolate the virus. This PEDV field strain, designated FL2013 strain, was successfully propagated and genetically characterized. The phylogenetic trees based upon either the complete genome or S gene showed that the FL2013 strain belongs to the genogroup G2b. The $\mathrm{S}$ gene of FL2013 has a 7-aa deletion (FEKVHVQ) in the C-terminus comparison with the other G2 PEDV sequences. Further comparative pathology study indicated that the FL2013 strain had reduced virulence to newborn piglets.

Conclusions: A novel variant PEDV strain FL2013 with reduced virulence, as determined by the pathological study, was identified from east China. This strain is closely related to the genogroup- 2 PEDV strains prevalent in the U.S. and China currently, but had a short deletion at the 3'- end of the spike gene.

Keywords: Porcine epidemic diarrhea virus, Variant, Reduced virulence

\section{Findings}

Porcine epidemic diarrhea virus (PEDV) is an enveloped, single-stranded, positive-sense RNA virus in the genus Alphacoronavirinae of the family Coronaviridae. PED, which is caused by PEDV, is characterized by severe diarrhea, dehydration, and high mortality rates in the affected swine [1]. PEDV variants belonging to genogroup 2 (G2) have been emerging in China in a large-scale outbreak characterized by approximately $80-100 \%$ morbidity rates and high mortality rates among suckling piglets since late 2010 [2]. Highly virulent PEDV strains, phylogenetically related to the G2 Chinese PEDV variants (shared $\geq 99.5 \%$ nt identity), suddenly

\footnotetext{
* Correspondence: yanhua_song@163.com; caoych@mail.sysu.edu.cn ${ }^{2}$ Guangdong Wen's Group Academy, Guangdong Wen's Foodstuffs Group Co., Ltd., Xinxing, Guangdong, China

'State Key Laboratory of Biocontrol, School of Life Sciences, Sun Yat-sen University, 510006 Guangzhou, P R China

Full list of author information is available at the end of the article
}

emerged in the United States in May 2013 and rapidly spread throughout the country, causing severe economic losses $[3,4]$. The second PEDV variant in the US, designated S INDEL PEDV, with insertions and deletions in the $\mathrm{N}$ terminal region ( $\mathrm{S} 1$ subunit) of the spike (S) protein same as the G1 PEDV, was identified subsequently [5]. The S INDEL strains caused reportedly milder disease in the field, indicating that the $\mathrm{S}$ gene contains major virulent determinants [6]. The other large S-deletion PEDV strains were also identified, including one Korean field strain with a 204-aa deletion [7], and a US cell-adapted strain with a 197-aa deletion [8]. Whether these S-deletion PEDV strains have distinct pathogenic characteristics, have not been described.

In July of 2013, fecal samples from diarrheal sows, collected in a pig farm in Jiangsu province of east China, were submitted to our lab for routine laboratory diagnostics. PEDV positivity was confirmed by reverse 
transcription PCR (RT-PCR) according to the method reported previously [2]. One of the PEDV-positive samples, from a sow with very mild clinical sign, was used to inoculate into Vero cells to isolate the virus, as described previously [2]. This PEDV strain, designated FL2013 strain, was successfully passaged and propagated, as characterized by typical PEDV-induced cytopathic effects (CPE), such as cell fusion and syncytia formation (data not shown), which was similar to what we observed for the CHGD-01 strains [2]. The other field PEDV samples collected from pigs with severe clinical sign could not adapt to Vero cells. The complete genomic cDNA of the FL2013 strain was further determined using the 3rd cell culture passaging virus by amplification of twelve regions covering the PEDV genome as described previously [2]. The sequences were assembled and analyzed using DNASTAR program and MEGA6.0 program [9].

The FL2013 PEDV genomic sequence had the size of 28,044 nt excluding the polyadenosine tail (GenBank accession no. KP765609). Twenty available PEDV sequences with complete genomes were used for multiple alignment and phylogenetic analysis (Table 1). The phylogenetic trees based upon either the complete genome (Fig. 1a) or S gene (Fig. 1b) showed that the FL2013 strain belongs to the genogroup G2b as proposed by Huang et al. [4]. The $\mathrm{S}$ gene harbors two significant insertions at aa 58 to $61(\mathrm{QGVN})$ and $142(\mathrm{~N})$, and a deletion of two aa (DI) between aa positions 167 and 168 at the Nterminus in comparison with the prototype CV777 strain (Fig. 2), which is the unique sequence signature of the virulent PEDV strains in the genogroup G2 [2-4]. However, the extreme C-terminus of the FL2013 S gene has a unique 21-nt deletion, leading to a 7-aa deletion (FEKVHVQ) in comparison with the other G2 PEDV sequences (Fig. 2). Interestingly, this unique deletion was also found in a G1 Korean strain SM98 (GenBank accession no. GU937797; Fig. 2). The complete $\mathrm{S}$ gene was sequenced in the original fecal sample, the 5th, 10th and 20th cell culture passages, respectively, and no sequence alterations were found, indicating that the 7-aa deletion was naturally present in the PEDV field strain and was stable in cell culture passaging. In addition, we did not find significant mutations on the other structural genes, non-structural genes and untranslated regions (UTR) potentially associated with attenuation.

Since the FL2013 strain was isolated from a sow with very mild clinical sign, we were interested to determine its virulence by experimental infection in newborn piglets in comparison with the virulent G2 strain. Thirty-six 3day-old piglets, negative for PEDV RNA were assigned into three groups with 12 in each. Piglets in each group were housed with their mothers (PEDV RNA and
Table 1 Summary of representative PEDV sequences used in this study

\begin{tabular}{|c|c|c|c|}
\hline Strain & Country & Accession no. & Full length \\
\hline CV777 & Belgium & AF353511 & $28033 \mathrm{bp}$ \\
\hline SM98 & Korea & GU937797 & 27994 bp \\
\hline Attenuated DR13 & Korea & JQ023162 & $27931 \mathrm{bp}$ \\
\hline Virulent DR13 & Korea & JQ023161 & 28029 bp \\
\hline LZC & China & EF185992 & 28042 bp \\
\hline $\mathrm{CH} / \mathrm{S}$ & China & JN547228 & $28026 \mathrm{bp}$ \\
\hline JS2008 & China & KC210146 & $27954 \mathrm{bp}$ \\
\hline SD-M & China & $J \times 560761$ & $27953 \mathrm{bp}$ \\
\hline CH/FJND-3/2011 & China & JQ282909 & $28038 \mathrm{bp}$ \\
\hline BJ-2011-1 & China & JN825712 & $28038 \mathrm{bp}$ \\
\hline CHGD-01 & China & JX261936 & 28047 bp \\
\hline AJ1102 & China & JX188454 & $28044 \mathrm{bp}$ \\
\hline FL2013 & China & KP765609 & $28044 \mathrm{bp}$ \\
\hline $\mathrm{CH} / \mathrm{GDGZ} / 2012$ & China & KF384500 & 28035 bp \\
\hline CH/FJZZ-9/2012 & China & KC140102 & $28038 \mathrm{bp}$ \\
\hline CH/ZMDZY/11 & China & KC196276 & $28038 \mathrm{bp}$ \\
\hline GD-1 & China & JX647847 & $28047 \mathrm{bp}$ \\
\hline ZJCZ4 & China & JX524137 & $28038 \mathrm{bp}$ \\
\hline LC & China & JX489155 & $28047 \mathrm{bp}$ \\
\hline GD-A & China & JX112709 & $28035 \mathrm{bp}$ \\
\hline GD-B & China & JX088695 & $28038 \mathrm{bp}$ \\
\hline JS-HZ2012 & China & KC210147 & $28037 \mathrm{bp}$ \\
\hline AH2012 & China & KC210145 & 28039 bp \\
\hline USA/Colorado/2013 & USA & KF272920 & $28038 \mathrm{bp}$ \\
\hline USA/lowa/18984/2013 & USA & KF804028 & $28039 \mathrm{bp}$ \\
\hline MN & USA & KF468752 & $28038 \mathrm{bp}$ \\
\hline ISU13-22038-IA-homogenate & USA & KF650373 & $28038 \mathrm{bp}$ \\
\hline ISU13-19338E-IN-homogenate & USA & KF650370 & $28038 \mathrm{bp}$ \\
\hline IA2 & USA & KF468754 & $28038 \mathrm{bp}$ \\
\hline$|A|$ & USA & KF468753 & $28038 \mathrm{bp}$ \\
\hline 13-019349 & USA & KF267450 & $28038 \mathrm{bp}$ \\
\hline
\end{tabular}

antibody negative) with no artificial supply of colostrum and milk. Group A serves as negative control, whereas piglets in groups $\mathrm{B}$ and $\mathrm{C}$ were challenged orally with the FL2013 strain and the virulent CHGD-01 strain [2] at $1.0 \times 10^{5} 50 \%$ tissue culture infectious doses $\left(\mathrm{TCID}_{50}\right) /$ $3 \mathrm{~mL}$, respectively. Two piglets from each group were euthanized and necropsied at 3 days post-inoculation (dpi) for histopathologic examinations and immunohistochemistry staining according to Stevenson et al. [10]. The remaining 10 piglets in each group were examined monitored for clinical signs and recorded to evaluate survival rate for $25 \mathrm{dpi}$. The result showed that Group-B piglets, together with the negative control group-A 


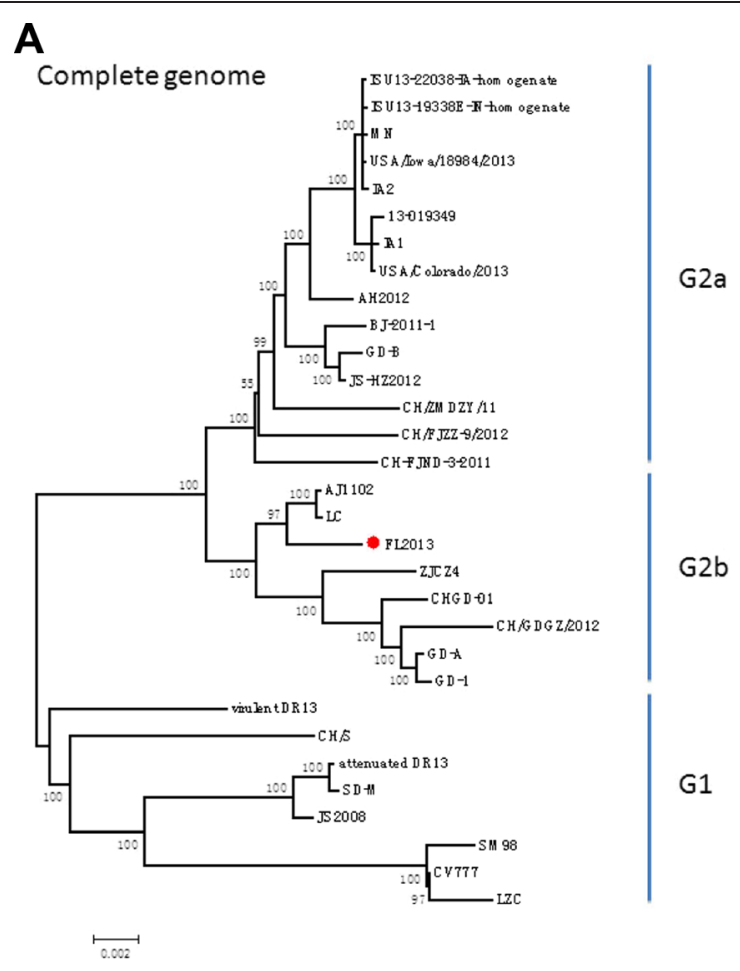

B

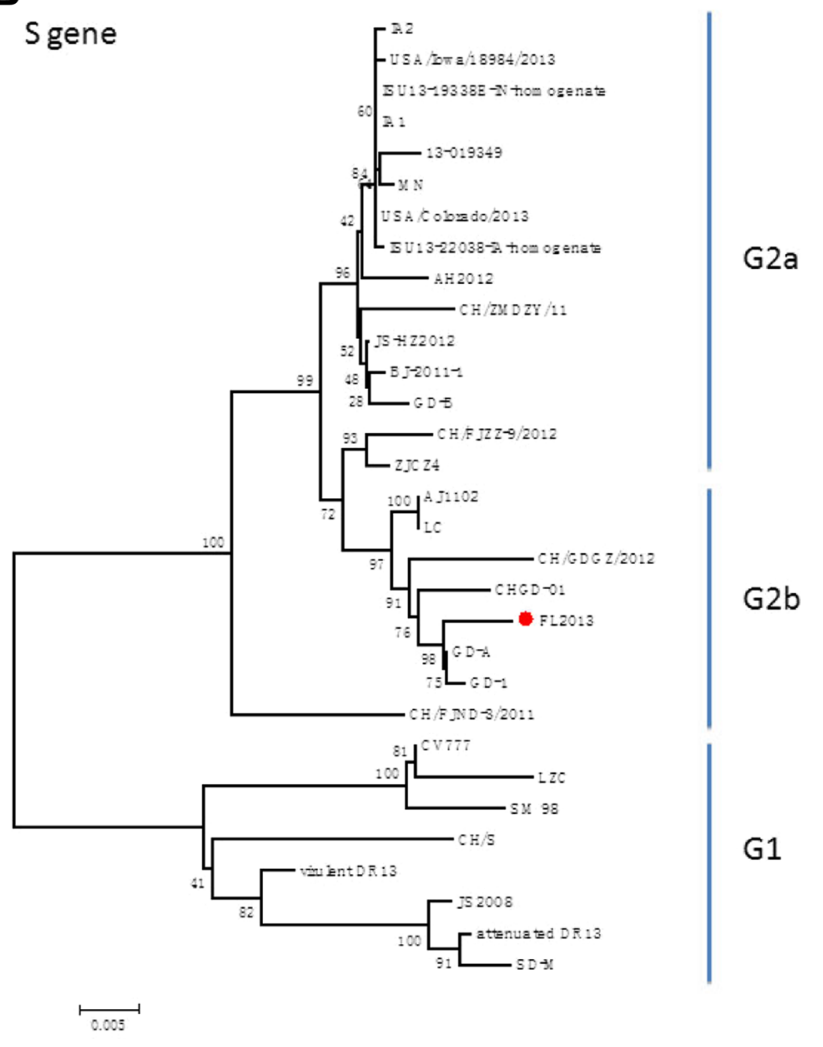

Fig. 1 Phylogenetic analyses of representative G1 and G2 PEDV strains based upon nucleotide sequences of the complete genome (a) and the S gene (b). The trees were constructed by the neighbor-joining method. Bootstrap values are indicated for each node from 1,000 resamplings. The names of the strains, countries of isolation, GenBank accession numbers, and genomic sizes are shown. Red filled circle indicate the PEDV FL2013 sequence in this study 


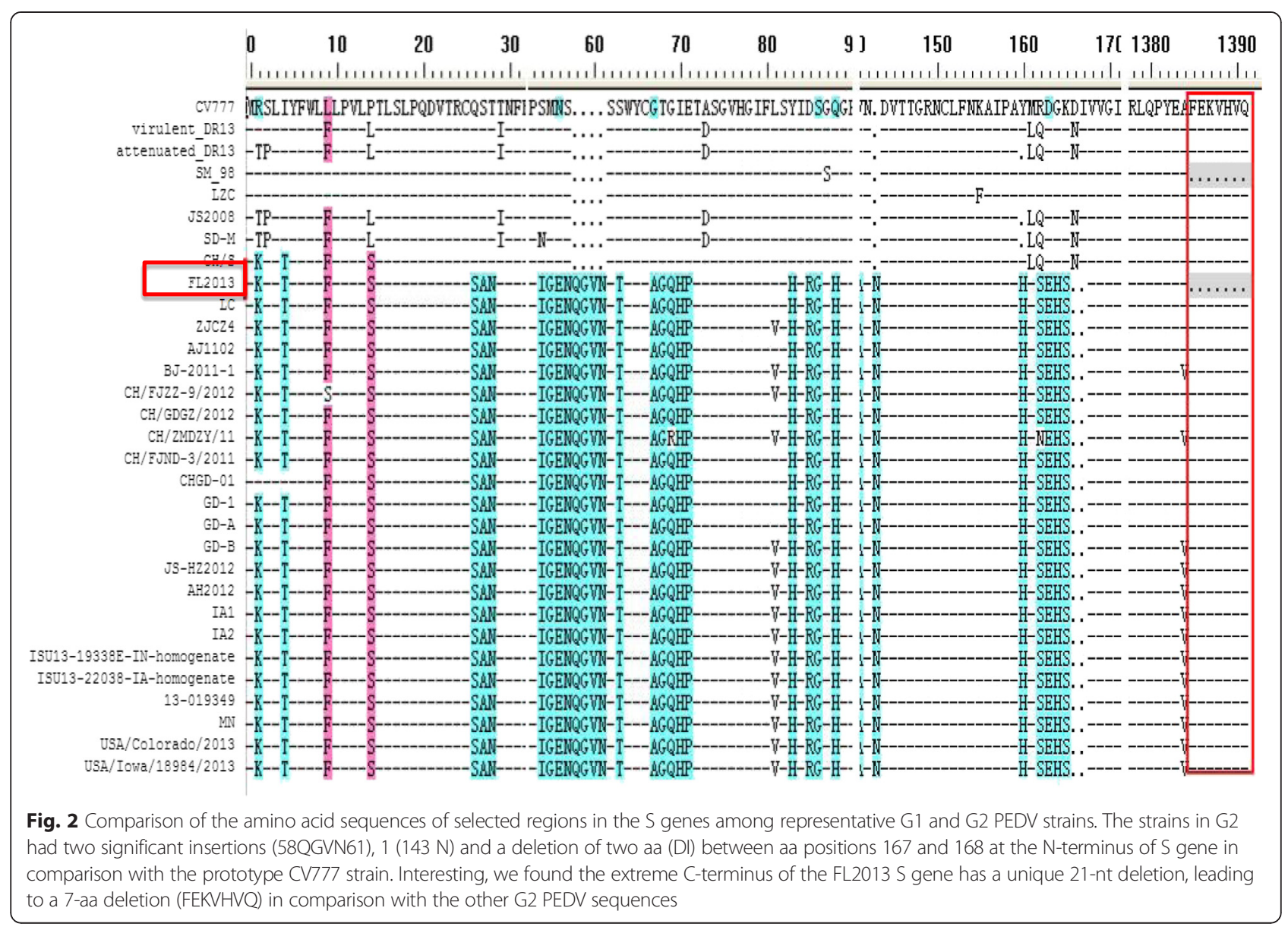

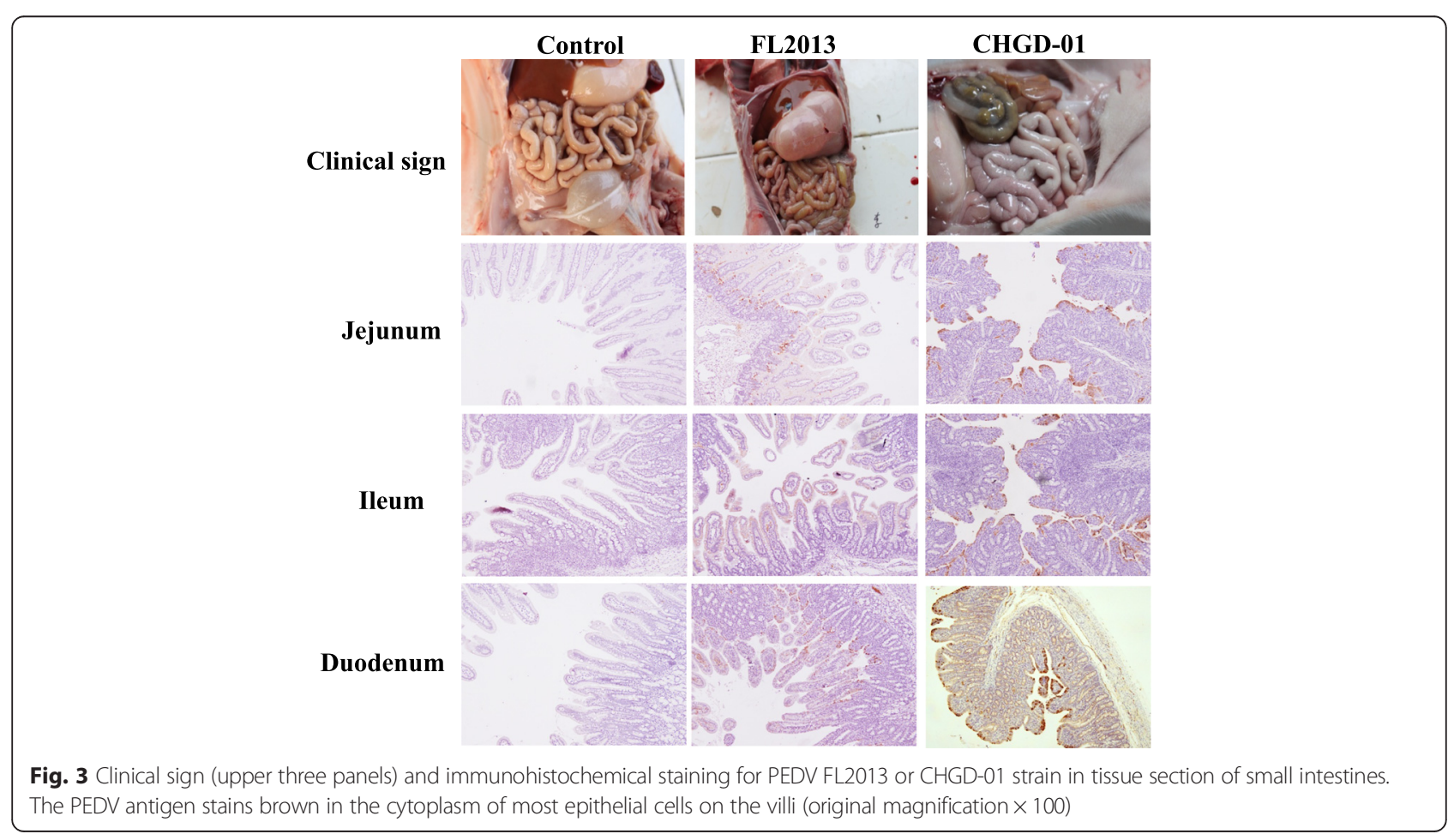


piglets did not show clinical sign, and all 10 remaining piglets in each group survived during the observation period (Fig. 3). Group-C piglets had PED signs characterized by acute vomiting and watery diarrhea, and immunohistochemistry staining showed abundant viral antigen in the severely atrophic villi (Fig. 3). In contrast, less PEDV positive staining was found in the intestinal villi of group-B samples, and the villi was only slightly damaged (Fig. 3). 10 of 10 remaining piglets in group C died within $7 \mathrm{dpi}$. The comparative pathology study indicated that the FL2013 strain had reduced virulence to newborn piglets.

In summary, we identified an apparently attenuated G2 PEDV field strain with 7-aa deletion at the 3 '-end of the $\mathrm{S}$ gene. Genetic characterizations of various PEDV field strains are of importance for demonstration of PEDV outbreaks and development of efficacy vaccines. Findings from present study reveals that variant PEDV strains circulating in swine-producing areas in China, and provides new molecular epidemiological data for a better understanding of this disease. It is highly possible that the sequence deletions (especially the 7-aa deletion), and other unknown mutations found in the variant strain FL2013 might have contributed to the reduced severity of the clinical disease in the piglets. Whether the changes in the genomic sequence, insertions and deletion, could collectively alter the efficiency of viral replication and RNA synthesis in the FL2013 strain leading to reduced pathogenicity will be investigated in further. More studies will be conducted to test this hypothesis. In addition, the FL2013 isolate may serve as a potential vaccine candidate that could protect the Chinese piglets from the infection caused by the virulent strain of PEDV.

\section{Competing interests}

The authors declare that they have no competing interests.

\section{Authors' contributions}

XBZ, YFP carried out most of the experiments and drafted the manuscript. YHS, YCC critically revised the manuscript and the experimental design. YXT and DDW contributed to the interpretation of the findings and revised the manuscript. All of the authors read and approved the final manuscript.

\section{Acknowledgements}

This work was supported by grants from the Wen's research fund of Guangdong Wen's Foodstuffs Group Co., Ltd (WSSC02-1-C-A-20120525-1327).

\footnotetext{
Author details

'State Key Laboratory of Biocontrol, School of Life Sciences, Sun Yat-sen University, 510006 Guangzhou, P R China. ${ }^{2}$ Guangdong Wen's Group Academy, Guangdong Wen's Foodstuffs Group Co., Ltd., Xinxing, Guangdong, China. ${ }^{3}$ College of Animal Science, South China Agricultural University, 510642 Guangzhou, China.
}

Received: 13 March 2015 Accepted: 27 May 2015

Published online: 12 June 2015

\section{References}

1. Song D, Park B. Porcine epidemic diarrhoea virus: a comprehensive review of molecular epidemiology, diagnosis, and vaccines. Virus Genes. 2012;44:167-75

2. Pan Y, Tian X, Li W, Zhou Q, Wang D, Bi Y, et al. Isolation and characterization of a variant porcine epidemic diarrhea virus in China. Virol J. 2012;9:195.

3. Marthaler D, Jiang Y, Otterson T, Goyal S, Rossow K, Collins J. Complete genome sequence of porcine epidemic diarrhea virus strain USA/Colorado/ 2013 from the United States. Genome Announc. 2013; 1. doi:10.1128/ genomeA.00555-13.

4. Huang YW, Dickerman AW, Pineyro P, Li L, Fang L, Kiehne R, et al. Origin, evolution, and genotyping of emergent porcine epidemic diarrhea virus strains in the United States. MBio. 2013;4:e713-37.

5. Wang L, Byrum B, Zhang Y. New variant of porcine epidemic diarrhea virus, United States, 2014. Emerg Infect Dis. 2014;20:917-9.

6. Vlasova AN, Marthaler D, Wang Q, Culhane MR, Rossow KD, Rovira A, et al. Distinct characteristics and complex evolution of PEDV strains, North America, May 2013-February 2014. Emerg Infect Dis. 2014;20:1620-8.

7. Park S, Kim S, Song D, Park B. Novel porcine epidemic diarrhea virus variant with large genomic deletion, South Korea. Emerg Infect Dis. 2014:20:2089-92.

8. Oka T, Saif LJ, Marthaler D, Esseili MA, Meulia T, Lin CM, et al. Cell culture isolation and sequence analysis of genetically diverse US porcine epidemic diarrhea virus strains including a novel strain with a large deletion in the spike gene. Vet Microbiol. 2014;173:258-69.

9. Tamura K, Stecher G, Peterson D, Filipski A, Kumar S. MEGA6: molecular evolutionary genetics analysis version 6.0. Mol Biol Evol. 2013;30:2725-9.

10. Stevenson GW, Hoang H, Schwartz KJ, Burrough ER, Sun D, Madson D, et al. Emergence of Porcine epidemic diarrhea virus in the United States: clinical signs, lesions, and viral genomic sequences. J Vet Diagn Invest. 2013;25:649-54.

\section{Submit your next manuscript to BioMed Central and take full advantage of:}

- Convenient online submission

- Thorough peer review

- No space constraints or color figure charges

- Immediate publication on acceptance

- Inclusion in PubMed, CAS, Scopus and Google Scholar

- Research which is freely available for redistribution 